\title{
FITOSSANIDADE
}

\section{EFEITO DA PODA DO TIPO DECOTE NO CONTROLE DA XYLELLA FASTIDIOSA EM CULTIVARES DE CAFEEIRO $\left({ }^{\mathbf{1}}\right)$}

\author{
RACHEL BENETTI QUEIROZ-VOLTAN $\left({ }^{2}\right)$; LUCIANE PEROSIN CABRAL $\left({ }^{3}\right)$; \\ OSVALDO PARADELA FILHO $\left({ }^{4}\right)$; LUIZ CARLOS FAZUOLI $\left({ }^{5,6}\right)$
}

\begin{abstract}
RESUMO
A bactéria Xylella fastidiosa causa prejuízos à cafeicultura e o emprego de produtos químicos, até o presente, não tem possibilitado o controle econômico dessa bactéria. O manejo adequado do cafezal, desde o plantio, com o uso de mudas isentas da bactéria e o controle das cigarrinhas vetoras, são medidas que atenuam a incidência da doença. A utilização de podas, que tem sido recomendada como medida de controle em citros e videiras, não tem ainda eficiência comprovada para o cafeeiro. Neste trabalho, objetivou-se estudar a eficácia do emprego da poda do tipo decote em cafeeiros arábica como controle de X. fastidiosa. Para tanto, após o emprego desse tipo de poda em cafeeiros infectados pela bactéria, quantificou-se a proporção de elementos de vaso do xilema obstruídos pela bactéria, e avaliou-se a severidade dos sintomas externos de infecção provocados pela X. fastidiosa. Oito meses após a aplicação da poda, no mês de junho de 2003 (período seco), observou-se que as plantas estavam com $4 \%$ dos elementos de vaso do pecíolo, $2 \%$ na nervura principal e $1 \%$ no caule obstruído pela $X$. fastidiosa. No período chuvoso, 14 meses após a poda, a proporção de obstrução dos elementos de vaso diminuiu para $2 \%$ no pecíolo, $1 \%$ no caule e na nervura principal. A prática da poda diminuiu ligeiramente a proporção de elementos de vaso obstruídos pela bactéria apenas no período seco, uma vez que foi observado antes da poda um máximo de $6 \%$ de obstrução no pecíolo. Os novos ramos que brotavam no cafeeiro, na estação chuvosa, pareciam compensar a obstrução dos ramos mais velhos, diminuindo a proporção de obstrução dos elementos de vaso na planta. Em 2003, não houve diferenças na severidade do sintoma externo entre os tratamentos nos dois períodos, seca e chuvoso. Entretanto, no período seco de 2004, as cultivares Catuaí Vermelho IAC 81 e Mundo Novo IAC 515-20, enxertadas sobre o porta-enxerto 'Apoatã IAC 2258' de C. canephora, foram os tratamentos com maior severidade e, novamente no período chuvoso, as diferenças não foram observadas. Concluiu-se, portanto, que a prática da poda do tipo decote não resultou nesse experimento em um controle eficiente da X. fastidiosa em cafeeiros de C. arabica de pé-franco ou enxertados e infectados por esta moléstia.
\end{abstract}

Palavras-chave: cultivares de Coffea arabica, porta-enxerto, obstrução do xilema, severidade.

$\left({ }^{1}\right)$ Com recursos complementares do Consórcio Brasileiro de Pesquisa e Desenvolvimento do Café. Recebido para publicação em 10 de março de 2005 e aceito em 15 de agosto de 2006.

$\left({ }^{2}\right)$ Núcleo de Pesquisa e Desenvolvimento do Jardim Botânico/CEC/IAC/APTA/SAA, Caixa Postal 28, $13012-970$ Campinas, SP. E-mail: rachelqv@iac.sp.gov.br

$\left({ }^{3}\right)$ Bolsista do Consórcio Brasileiro de Pesquisa e Desenvolvimento do Café.

$\left({ }^{4}\right)$ Centro de Pesquisa e Desenvolvimento de Fitossanidade, IAC. Aposentado.

$\left({ }^{5}\right)$ Centro de Análise e Pesquisa Tecnológica do Agronegócio do Café Alcides Carvalho, IAC.

$\left({ }^{6}\right)$ Com bolsa de produtividade em pesquisa do CNPq. 


\section{ABSTRACT \\ “DECOTE” TYPE PRUNING EFFECT UPON XYLELLA FASTIDIOSA CONTROL IN COFFEE CULTIVARS}

Xylella fastidiosa plant colonization causes damages to the coffee production and nowadays there is no available economic chemical control to this bacterium. Adequate cultivation management as the use of bacteria-free scions and control of the insect vector (cicadas), are practices that may attenuate the disease incidence. Pruning, that has been recommended for citrus and vines for disease control, still does not have its efficiency proved for coffee plants. This research work aimed to quantify the proportion of xylem vessel elements obstructed by the bacteria, as well as to evaluate the disease external symptoms severity after the "decote" type pruning. In June 2003 (dry season), eight months after pruning, it was observed that $4 \%$ of the petiole vessel elements were obstructed by $X$. fastidiosa, $2 \%$ of the central vein and $1 \%$ of the stem. In the rainy season, 14 months after pruning, the obstruction proportion of vessel elements decreased to $2 \%$ in the petiole and to $1 \%$ in central vein and stem respectively. Therefore, the pruning practice decreased slightly the xylem vessel obstruction caused by the bacteria in the dry period, once prior to pruning a $6 \%$ obstruction in the petiole was observed. The new branches sprouted during the rainy season seemed to compensate obstruction in older branches, thus decreasing vase obstruction proportion. In 2003 there were no differences in the disease symptom severity among treatments in the two periods (dry and rainy season), however, in the dry period of 2004, 'Catuaí Vermelho IAC 81' and 'Mundo Novo IAC 515-20' cultivars, grafted on C. canephora 'Apoatã IAC 2258', presented higher severity and, again in the rainy period, differences were not observed. It was concluded that the "decote" type pruning practice did not result in a $X$. fastidiosa efficient control.

Key words: C. arabica cultivars, grafted, xylem obliteration, severity.

\section{INTRODUÇÃO}

A bactéria Xylella fastidiosa Wells et al. vem causando prejuízos a diversas culturas economicamente importantes desde 1892, quando foi detectada na Califórnia, em espécimes de videira (Pierce, 1892). No Brasil, tem causado prejuízos até de $35 \%$ na cultura de citros, enquanto na cafeicultura, embora não tenha sido quantificada sua significância econômica, registrou-se em São José do Rio Preto (SP), uma redução de $30 \%$ na produção, em algumas plantações (PRATO, 2000). Essa bactéria está disseminada, de modo geral, por todas as áreas produtivas de cafeeiro em São Paulo e outros Estados brasileiros.

A grande maioria dos hospedeiros naturais dessa bactéria ocorre na Flórida e pertence a 28 famílias botânicas, incluindo mono e dicotiledôneas, sendo muitas hospedeiras assintomáticas (HopKINs e Adlerz, 1988). X. fastidiosa é transmitida por cigarrinhas das famílias Cicadellidae (subfamília Cicadellinae) e Cercopidae, que se alimentam dos ramos e folhas, preferencialmente nos tecidos do xilema (Hopkins, 1989; LoPes, 1996; PaIva et al., 1996).

Os principais sintomas morfológicos externos dessa doença em cafeeiro são: entrenós mais curtos, tornando as folhas próximas entre si, conferindo-lhes um aspecto de roseta; diminuição no comprimento dos pecíolos e de área foliar; senescência das folhas mais maduras, resultando em ramos com pequeno número de folhas no seu ápice. Devido ao encurtamento dos pedicelos e dos entrenós, as flores e frutos ficam agrupados e também há redução no seu tamanho (Paradela Filho et al., 1995, 1999; QueIrozVOLTAN et al., 1998). Internamente, ocorre deposição de "goma" nos vasos do xilema e foram observadas divisões anormais em células do mesofilo, xilema, floema e córtex do pecíolo e caule de ramos com sintomas externos severos. Nas folhas sintomáticas observa-se um número reduzido de cloroplastos, associado à maior concentração de cristais de oxalato de cálcio (Queiroz-Voltan et al., 1998). Essa doença em cafeeiro também é conhecida como requeima, escaldadura do cafeeiro ou atrofia dos ramos do cafeeiro (Paradela Filho et al., 1999).

A causa principal dos sintomas tem sido atribuída à disfunção do sistema condutor de água, relacionada com a oclusão de elementos de vaso do xilema por "gomas", tiloses ou células bacterianas (Esau, 1948; Mircetich et al., 1976; Mollenhauer e HoPKINS, 1976). Existem, porém, divergências na literatura se essas oclusões seriam suficientes para causar estresse hídrico (MirCETICH et al., 1976; FrENCH e Stassi, 1978; HopKINS, 1981). Outras duas hipóteses para a origem dos sintomas da doença são a da fitotoxina (Mircetich et al., 1976; LeE et al., 1982) e a do desbalanço de reguladores de crescimento (FRENCH e STASSI, 1978). Em Citrus sinensis L., a obstrução do xilema causa provavelmente menor suprimento de água no mesofilo, diminuindo as taxas de fotossíntese e de transpiração, acompanhado de baixa eficiência de carboxilação e distúrbios fotoquímicos nas plantas 
doentes (Habermann et al., 2003; MAchado et al, 1994). Há muitos anos, o cafeeiro vem apresentando sintomas de infecção pela Xylella, os quais, entretanto, eram atribuídos a estresse nutricional devido a altas produções (Paradela Filho et al, 1997). O efeito dessa bactéria na anatomia da planta foi descrito por Queiroz-Voltan et al. (1998), e discutiu-se a forte evidência de uma relação entre a $X$. fastidiosa e senescência, associadas a fatores de estresse.

O emprego de produtos químicos não tem permitido o controle econômico dessa doença e, até o momento, o manejo adequado do cafezal, desde o plantio, com o uso de mudas sadias, e o controle das cigarrinhas vetoras, são medidas que atenuam a incidência da moléstia (ThomAziello et al., 2000). A utilização de podas recomendada para citros (Feichtenberger et al., 1997) e videiras (Weber et al., 2000, 2002), não tem ainda eficiência comprovada para o cafeeiro.

A poda em cafeeiro é uma técnica utilizada para eliminar ramos improdutivos (THOMAZIELLo et al., 2000). Os ramos com sintomas avançados da doença ocasionada pela X. fastidiosa, isto é, com folhas concentradas no ápice, devido à senescência de folhas na base e, crescimento secundário no caule (presença de súber) são ramos improdutivos, ideais para o emprego dessa prática.

Neste trabalho, objetivou-se estudar a eficácia do emprego da poda do tipo decote em cultivares de cafeeiro arábica enxertados ou de pé-franco, como controle de X. fastidiosa. Para tanto, após o emprego desse tipo de poda em cafeeiros sintomáticos, quantificou-se a proporção de elementos de vaso do xilema obstruídos, bem como a severidade dos sintomas externos de infecção provocados pela $X$. fastidiosa.

\section{MATERIAL E MÉTODOS}

Foi utilizado um experimento de cafeeiros enxertados, instalado em 1986 na Fazenda da Mata, município de Garça (latitude $22^{\circ} 12^{\prime} \mathrm{S}$, longitude $49^{\circ}$ $39^{\prime} \mathrm{W}$ e altitude $663 \mathrm{~m}$ ), Estado de São Paulo. O delineamento utilizado foi o de blocos ao acaso, com dez tratamentos e cinco repetições, sendo o espaçamento de $3,5 \times 2,0 \mathrm{~m}$ e as parcelas de quatro covas, cada uma com duas plantas. Como portaenxerto, utilizaram-se duas progênies de Coffea canephora Pierre ex A. Froehner - Apoatã IAC 2258 e Robusta IAC 2286 - e uma de C. congensis A. Froehner - IAC Bangelan coleção 5. Atualmente acredita-se ser derivado de hibridação entre $C$. congensis e $C$. canephora. Como enxerto, empregaram-se duas cultivares de C. arabica L. - Catuaí Vermelho IAC 81 e Mundo Novo IAC 515-20. As progênies utilizadas como porta-enxerto foram oriundas de plantas matrizes selecionadas pelo Centro de Análise e Pesquisa Tecnológica do Agronegócio do Café Alcides Carvalho, IAC/APTA, em áreas infestadas por nematóides. Efetuaram-se, também, auto-enxertias em cafeeiro das cultivares Catuaí Vermelho IAC 81 e Mundo Novo IAC 515-20, considerando-se as plantas não enxertadas dessas cultivares como testemunha.

O experimento foi desenvolvido nas condições ideais de adubação, calagem e de tratos culturais recomendados para seu desenvolvimento (RAIJ et al., 1997). Em outubro de 2002, as plantas foram submetidas à poda do tipo decote, que consistiu na eliminação do ápice da planta à altura de 1,60 metros.

As amostras para o estudo anatômico foram retiradas em junho e dezembro de 2003, correspondentes aos períodos seco e chuvoso, respectivamente. Utilizaram-se cinco plantas, aleatoriamente, de cada tratamento, sendo uma planta representativa de cada parcela. No período seco essas plantas estavam com sintomas de níveis 1 ou 2 de severidade e no chuvoso de 1 a 3 (Tabela $3)$. De cada planta, retiraram-se cinco ramos aleatórios do lado poente do sol, onde os sintomas eram mais severos, dos quais foram obtidos segmentos de $0,5 \mathrm{~cm}$ de comprimento de caule e do pecíolo, além de $0,25 \mathrm{~cm}^{2}$ da região da nervura principal, na porção mediana da lâmina de folhas adultas. Os segmentos do caule e das folhas foram retirados da região do ramo entre o $3 .^{\circ}$ e $4 .^{\circ}$ nós, e fixados em solução etílica $(50 \%)$ de formaldeídoácido acético (F.A.A. 50\%) (JoHANSEN, 1940). Posteriormente, as amostras de pecíolo e limbo foram colocadas em parafina e seccionadas transversalmente em micrótomo de rotação; as de caule foram seccionadas em criostato a $-28^{\circ} \mathrm{C}$.

A espessura das secções foi de $12 \mathrm{~mm}$ e a coloração utilizada, a de safranina-alcian blue, modificada por GABRIELLI (1992). A obstrução de elementos de vaso do xilema foi estudada nos diferentes órgãos, totalizando 150 observações por amostra. A proporção foi estimada, considerando-se o número de elementos de vasos que estavam total ou parcialmente obstruídos por "goma", em relação ao número total de elementos de vaso, por campo de área conhecida. Uma vez que a proporção de elementos de vaso obstruídos apresentou distribuição binomial, foram estimadas as respectivas médias e o desviopadrão dos tratamentos, os quais foram comparados pelos intervalos de confiança, a 5\% de significância (SOKAL e RohlF, 1981). 
Avaliou-se também a severidade dos sintomas utilizando-se uma escala de notas de 1 a 4 , de acordo com os seguintes critérios: nota 1 - de $1 \%$ a $25 \%$ dos ramos com sintoma morfológico externo de presença da bactéria (planta aparentemente sadia); 2 - de $26 \%$ a $50 \%$ dos ramos com sintomas (planta pouco infectada); nota 3 - 51\% a $75 \%$ dos ramos com sintoma (planta moderadamente infectada) e nota 4 - de $76 \%$ a $100 \%$ de ramos com sintoma (planta muito infectada). Nas áreas de experimentação, não havia plantas com $0 \%$ de ramos com sintoma da presença da bactéria. A observação visual foi feita na planta toda.

A severidade foi avaliada após 2, 8, 14, 20 e 26 meses da realização da poda do tipo decote. Cinqüenta plantas fizeram parte de cada amostra, pertencentes a 10 tratamentos retirados de cada uma das cinco parcelas. Confirmou-se a presença da bactéria nessas plantas, através da microscopia ótica e eletrônica, apesar da evidência morfológica externa, descrita anteriormente, ter sido observada. Os resultados foram analisados por meio do teste não paramétrico de Friedman (GoMEs, 1990, SPRENT, 1996) e a significância do teste foi considerada a $1 \%$ e $5 \%$.

\section{RESULTADOS E DISCUSSÃO}

A principal finalidade da poda do cafeeiro é eliminar ramos improdutivos, visando modificar a arquitetura da planta, mantendo adequada a relação frutos e folhas; estimular a produção devido à maior penetração de luz; controlar pragas e doenças, pela redução das condições favoráveis aos agentes transmissores, como luz e ar; eliminar ramos afetados por pragas e doenças; entre outros (THOMAZIELLO et al., 2000). Ramos com sintoma avançado da doença, isto é, com folhas concentradas no ápice, devido à senescência de folhas na base, e crescimento secundário no caule (presença de súber) são ramos improdutivos e, portanto, ideais para o emprego dessa técnica.

Neste trabalho, oito meses após a poda, em junho de 2003 e, portanto, período seco, observou-se que $4 \%$ dos elementos de vaso do pecíolo estavam obstruídos, $2 \%$ na nervura principal e $1 \%$ no caule (Tabela 1), valores menores do que o observado no mesmo mês de 2000, antes da poda, onde se observou $6 \%$ de obstrução no pecíolo e caule e 3\% na nervura principal (QueIROZ-VOLTAN et al, 2004a). No período chuvoso de 2003, 14 meses após a poda (Tabela 2), a proporção de obstrução dos elementos de vaso diminuiu para $2 \%$ no pecíolo, $1 \%$ no caule e nervura principal, resultado semelhante ao observado no mesmo período de 2000 (QueIroz-Voltan et al, 2004a). Portanto, a prática da poda do tipo decote diminuiu ligeiramente a proporção de obstrução de elementos de vaso ocasionados pela bactéria, apenas no período seco.
É importante ressaltar que os ramos amostrados foram retirados da planta toda do lado poente do sol onde se observou maior severidade dos sintomas. Optou-se por não amostrar apenas os ramos rebrotados após o decote, já relatado em trabalhos anteriores (QueIROz-VOLTAN et al, 2004a; QueIROZVolTAN et al, 2005), pois ramos sem sintomas externos têm menores proporções de elementos de vaso obstruídos pela bactéria. Ademais, neste trabalho, o interesse era avaliar a planta toda após a prática desse tipo de poda.

A explicação sugerida para maior oclusão dos elementos de vaso no pecíolo em relação à nervura foliar é que o movimento da $X$. fastidiosa ocorre da base para o ápice, colonizando primeiramente os pecíolos e limitando o movimento da água para dentro da folha (McElrone et al, 2003).

Os novos ramos que brotavam no cafeeiro na estação chuvosa pareciam compensar a obstrução dos ramos mais velhos, diminuindo a proporção de obstrução dos elementos de vaso na planta.

Quando se comparou a proporção de obstrução dos elementos de vaso entre os tratamentos nas folhas (pecíolo e nervura principal) e caule, observou-se que não havia diferenças entre eles (Tabelas 1 e 2), resultados que corroboram com os obtidos antes do emprego da poda (QueIROZ-VOLTAN et al., 2004a).

Em 2003, observou-se que as diferenças na severidade do sintoma externo entre os tratamentos nos dois períodos, de seca e chuvoso eram inexistentes (Tabela 3). Entretanto, no período seco de 2004 (Tabela 4), as cultivares Catuaí Vermelho IAC 81 e Mundo Novo IAC 515-20 enxertadas sobre o portaenxerto Apoatã IAC 2258 foram os tratamentos com maior severidade, enquanto nos tratamentos de péfranco, houve menor severidade dos sintomas externos. No período chuvoso de 2004, também não houve diferenças na severidade entre os tratamentos.

Os estudos sobre a infecção da X. fastidiosa no cafeeiro têm sido efetuados principalmente em cultivares de C. arabica de pé-franco. Há poucas informações sobre o comportamento de outras espécies de Coffea, ou mesmo, sobre plantas enxertadas. Neste estudo utilizaram-se cultivares de C. arabica enxertadas principalmente em $C$. canephora porque a enxertia tem sido utilizada com sucesso para substituir o sistema radicular de cultivares de C. arabica, suscetíveis ao ataque de fungos, nematóides e outros patógenos das raízes. Além disso, a utilização de linhagens de $C$. canephora, tolerantes a nematóides como porta-enxerto para cultivares de C. arabica, aumentam consideravelmente a produção das plantas enxertadas estabelecidas em solos infestados por esses patógenos (FAZUOLI et al.,1983). 
Tabela 1. Média, desvio-padrão e intervalo de confiança das estimativas de obstrução de elementos de vaso do xilema obtidas na nervura principal, pecíolo e caule de cafeeiros de pé-franco e enxertados após 8 meses de poda do tipo decote, em Garça (SP), junho/2003 (período de seca)

\begin{tabular}{|c|c|c|c|}
\hline \multirow{2}{*}{ Tratamentos $\left({ }^{1}\right)$} & \multicolumn{3}{|c|}{ Obstrução de elementos de vaso do xilema } \\
\hline & Média & Desvio-padrão & Intervalos de confiança \\
\hline \multicolumn{4}{|c|}{ Nervura Principal } \\
\hline Catuaí/Apoatã & 0,034 & 0,058 & $(0,005 \leq \Pi \leq 0,063)$ \\
\hline Catuaí/ Bangelan & 0,033 & 0,051 & $(0,004 \leq \Pi \leq 0,061)$ \\
\hline Catuaí/ Robusta & 0,037 & 0,047 & $(0,007 \leq \Pi \leq 0,067)$ \\
\hline Mundo Novo/Apoatã & 0,024 & 0,055 & $(-0,001 \leq \Pi \leq 0,049)$ \\
\hline Mundo Novo/Bangelan & 0,008 & 0,024 & $(-0,006 \leq \Pi \leq 0,022)$ \\
\hline Mundo Novo/ Robusta & 0,014 & 0,031 & $(-0,005 \leq \Pi \leq 0,032)$ \\
\hline Catuaí/ Catuaí & 0,029 & 0,052 & $(0,002 \leq \Pi \leq 0,055)$ \\
\hline Mundo Novo/ Mundo Novo & 0,020 & 0,038 & $(-0,003 \leq \Pi \leq 0,042)$ \\
\hline Mundo Novo (testemunha) & 0,014 & 0,036 & $(-0,005 \leq \Pi \leq 0,032)$ \\
\hline Catuaí (testemunha) & 0,008 & 0,026 & $(-0,006 \leq \Pi \leq 0,023)$ \\
\hline Média Total & 0,022 & 0,044 & - \\
\hline \multicolumn{4}{|c|}{ Pecíolo } \\
\hline Catuaí/Apoatã & 0,045 & 0,063 & $(0,012 \leq \Pi \leq 0,078)$ \\
\hline Catuaí/ Bangelan & 0,059 & 0,075 & $(0,022 \leq \Pi \leq 0,097)$ \\
\hline Catuaí/ Robusta & 0,079 & 0,115 & $(0,036 \leq \Pi \leq 0,122)$ \\
\hline Mundo Novo/Apoatã & 0,033 & 0,055 & $(0,004 \leq \Pi \leq 0,061)$ \\
\hline Mundo Novo/Bangelan & 0,019 & 0,045 & $(-0,003 \leq \Pi \leq 0,040)$ \\
\hline Mundo Novo/ Robusta & 0,031 & 0,068 & $(0,003 \leq \Pi \leq 0,059)$ \\
\hline Catuaí/ Catuaí & 0,025 & 0,046 & $(-0,001 \leq \Pi \leq 0,049)$ \\
\hline Mundo Novo/ Mundo Novo & 0,031 & 0,056 & $(0,003 \leq \Pi \leq 0,058)$ \\
\hline Mundo Novo (testemunha) & 0,025 & 0,053 & $(-0,001 \leq \Pi \leq 0,049)$ \\
\hline Catuaí (testemunha) & 0,013 & 0,036 & $(-0,005 \leq \Pi \leq 0,031)$ \\
\hline Média Total & 0,036 & 0,067 & - \\
\hline \multicolumn{4}{|c|}{ Caule } \\
\hline Catuaí/Apoatã & 0,012 & 0,033 & $(-0,005 \leq \Pi \leq 0,030)$ \\
\hline Catuaí/ Bangelan & 0,012 & 0,031 & $(-0,005 \leq \Pi \leq 0,030)$ \\
\hline Catuaí/ Robusta & 0,014 & 0,048 & $(-0,005 \leq \Pi \leq 0,033)$ \\
\hline Mundo Novo/Apoatã & 0,003 & 0,013 & $(-0,006 \leq \Pi \leq 0,012)$ \\
\hline Mundo Novo/Bangelan & 0,003 & 0,011 & $(-0,006 \leq \Pi \leq 0,011)$ \\
\hline Mundo Novo/ Robusta & 0,003 & 0,014 & $(-0,006 \leq \Pi \leq 0,011)$ \\
\hline Catuaí/ Catuaí & 0,008 & 0,020 & $(-0,006 \leq \Pi \leq 0,021)$ \\
\hline Mundo Novo/ Mundo Novo & 0,009 & 0,024 & $(-0,006 \leq \Pi \leq 0,023)$ \\
\hline Mundo Novo (testemunha) & 0,008 & 0,026 & $(-0,006 \leq \Pi \leq 0,022)$ \\
\hline Catuaí (testemunha) & 0,003 & 0,015 & $(-0,006 \leq \Pi \leq 0,013)$ \\
\hline Média Total & 0,007 & 0,026 & - \\
\hline
\end{tabular}

( ${ }^{1}$ ) Catuaí = 'Catuaí Vermelho IAC 81'; Apoatã = 'Apoatã IAC 2258' (porta-enxerto); Mundo Novo = 'Mundo Novo IAC 515-20'; Bangelan = C. congensis 'Bangelan col. 5' (porta-enxerto); Robusta = 'Robusta IAC 2286'(porta-enxerto). 
Tabela 2. Média, desvio-padrão e intervalo de confiança das estimativas de obstrução de elementos de vaso do xilema obtidas na nervura principal, pecíolo e caule de cafeeiros de pé-franco e enxertados após 14 meses de poda do tipo decote em Garça (SP) em dezembro/2003 (período chuvoso)

\begin{tabular}{|c|c|c|c|}
\hline \multirow{2}{*}{ Tratamentos $\left({ }^{1}\right)$} & \multicolumn{3}{|c|}{ Obstrução de elementos de vaso do xilema } \\
\hline & Média & Desvio-padrão & Intervalos de confiança \\
\hline \multicolumn{4}{|c|}{ Nervura Principal } \\
\hline Catuaí/Apoatã & 0,006 & 0,018 & $(-0,006 \leq \Pi \leq 0,018)$ \\
\hline Catuaí/ Bangelan & 0,014 & 0,029 & $(-0,005 \leq \Pi \leq 0,032)$ \\
\hline Catuaí/ Robusta & 0,017 & 0,041 & $(-0,004 \leq \Pi \leq 0,038)$ \\
\hline Mundo Novo/Apoatã & 0,008 & 0,021 & $(-0,006 \leq \Pi \leq 0,022)$ \\
\hline Mundo Novo/Bangelan & 0,006 & 0,035 & $(-0,006 \leq \Pi \leq 0,017)$ \\
\hline Mundo Novo/ Robusta & 0,006 & 0,029 & $(-0,006 \leq \Pi \leq 0,018)$ \\
\hline Catuaí/ Catuaí & 0,003 & 0,024 & $(-0,006 \leq \Pi \leq 0,012)$ \\
\hline Mundo Novo/ Mundo Novo & 0,005 & 0,022 & $(-0,006 \leq \Pi \leq 0,016)$ \\
\hline Mundo Novo (testemunha) & 0,009 & 0,039 & $(-0,006 \leq \Pi \leq 0,024)$ \\
\hline Catuaí (testemunha) & 0,009 & 0,023 & $(-0,006 \leq \Pi \leq 0,023)$ \\
\hline Média Total & 0,008 & 0,029 & - \\
\hline \multicolumn{4}{|c|}{ Pecíolo } \\
\hline Catuaí/Apoatã & 0,011 & 0,032 & $(-0,006 \leq \Pi \leq 0,027)$ \\
\hline Catuaí/ Bangelan & 0,038 & 0,087 & $(0,007 \leq \Pi \leq 0,068)$ \\
\hline Catuaí/ Robusta & 0,034 & 0,065 & $(0,005 \leq \Pi \leq 0,063)$ \\
\hline Mundo Novo/Apoatã & 0,027 & 0,063 & $(0,001 \leq \Pi \leq 0,053)$ \\
\hline Mundo Novo/Bangelan & 0,008 & 0,025 & $(-0,006 \leq \Pi \leq 0,021)$ \\
\hline Mundo Novo/ Robusta & 0,013 & 0,041 & $(-0,005 \leq \Pi \leq 0,030)$ \\
\hline Catuaí/ Catuaí & 0,015 & 0,053 & $(-0,004 \leq \Pi \leq 0,034)$ \\
\hline Mundo Novo/ Mundo Novo & 0,006 & 0,024 & $(-0,006 \leq \Pi \leq 0,018)$ \\
\hline Mundo Novo (testemunha) & 0,008 & 0,036 & $(-0,006 \leq \Pi \leq 0,023)$ \\
\hline Catuaí (testemunha) & 0,021 & 0,057 & $(-0,002 \leq \Pi \leq 0,044)$ \\
\hline Média Total & 0,018 & 0,053 & - \\
\hline \multicolumn{4}{|c|}{ Caule } \\
\hline Catuaí/Apoatã & 0,008 & 0,048 & $(-0,006 \leq \Pi \leq 0,022)$ \\
\hline Catuaí/ Bangelan & 0,009 & 0,036 & $(-0,006 \leq \Pi \leq 0,023)$ \\
\hline Catuaí/ Robusta & 0,008 & 0,021 & $(-0,006 \leq \Pi \leq 0,023)$ \\
\hline Mundo Novo/Apoatã & 0,021 & 0,074 & $(-0,002 \leq \Pi \leq 0,044)$ \\
\hline Mundo Novo/Bangelan & 0,007 & 0,056 & $(-0,006 \leq \Pi \leq 0,020)$ \\
\hline Mundo Novo/ Robusta & 0,009 & 0,047 & $(-0,006 \leq \Pi \leq 0,024)$ \\
\hline Catuaí/ Catuaí & 0,016 & 0,053 & $(-0,004 \leq \Pi \leq 0,036)$ \\
\hline Mundo Novo/ Mundo Novo & 0,009 & 0,039 & $(-0,006 \leq \Pi \leq 0,024)$ \\
\hline Mundo Novo (testemunha) & 0,001 & 0,007 & $(-0,004 \leq \Pi \leq 0,005)$ \\
\hline Catuaí (testemunha) & 0,023 & 0,075 & $(-0,001 \leq \Pi \leq 0,047)$ \\
\hline Média Total & 0,011 & 0,051 & - \\
\hline
\end{tabular}

$\left({ }^{1}\right)$ Catuaí = 'Catuaí Vermelho IAC 81'; Apoatã = 'Apoatã IAC 2258' (porta-enxerto); Mundo Novo = 'Mundo Novo IAC 515-20'; Bangelan = C. congensis 'Bangelan col. 5' (porta-enxerto); Robusta = 'Robusta IAC 2286' (porta-enxerto). 
Tabela 3. Níveis de severidade ocasionados pela bactéria Xylella fastidiosa em cultivares de cafeeiros de pé-franco e enxertados após a poda do tipo decote, Garça (SP) em 2003, nos períodos de seca e chuvoso

\begin{tabular}{|c|c|c|c|c|c|c|c|c|c|}
\hline \multirow[t]{2}{*}{ Tratamentos $\left({ }^{1}\right)$} & \multicolumn{5}{|c|}{$\begin{array}{c}\text { Notas referentes a níveis de severidades } \\
\text { nas parcelas }\left({ }^{2}\right)\end{array}$} & \multicolumn{4}{|c|}{ Parâmetros estatísticos $\left({ }^{3}\right)$} \\
\hline & A & $\mathrm{B}$ & $\mathrm{C}$ & $\mathrm{D}$ & $\mathrm{E}$ & Mediana & $\mathrm{R}$ & $\mathrm{K} 1$ & $\mathrm{P}$ \\
\hline & \multicolumn{8}{|c|}{ Período de seca } & \\
\hline Catuaí/ Apoatã & 1 & 2 & 1 & 1 & 2 & 1,40 & 25,0 & 12,58 & $0,182 \mathrm{NS}$ \\
\hline Catuaí/ Bangelan & 1 & 2 & 2 & 1 & 2 & 1,70 & 29,5 & & \\
\hline Catuaí/ Robusta & 2 & 1 & 3 & 2 & 1 & 1,90 & 31,0 & & \\
\hline Mundo Novo/Apoatã & 2 & 2 & 1 & 2 & 1 & 1,70 & 30,0 & & \\
\hline Mundo Novo/Bangelan & 2 & 2 & 1 & 1 & 1 & 1,50 & 25,0 & & \\
\hline Mundo Novo/ Robusta & 1 & 1 & 1 & 1 & 1 & 1,00 & 15,0 & & \\
\hline Catuaí/ Catuaí & 2 & 2 & 2 & 2 & 2 & 2,00 & 39,5 & & \\
\hline Mundo Novo/Mundo Novo & 1 & 1 & 1 & 2 & 1 & 1,30 & 20,0 & & \\
\hline Mundo Novo & 2 & 2 & 1 & 1 & 2 & 1,80 & 30,0 & & \\
\hline \multirow[t]{2}{*}{ Catuaí } & 2 & 2 & 1 & 2 & 1 & 1,70 & 30,0 & & \\
\hline & \multicolumn{8}{|c|}{ Período chuvoso } & \\
\hline Catuaí/Apoatã & 2 & 3 & 3 & 1 & 1 & 2,10 & 30,5 & 9,37 & $0,404 \mathrm{NS}$ \\
\hline Catuaí/ Bangelan & 2 & 2 & 3 & 1 & 1 & 1,90 & 27,0 & & \\
\hline Catuaí/ Robusta & 1 & 2 & 2 & 3 & 1 & 1,90 & 27,5 & & \\
\hline Mundo Novo/ Apoatã & 2 & 3 & 1 & 2 & 3 & 2,30 & 36,5 & & \\
\hline Mundo Novo/Bangelan & 1 & 2 & 3 & 2 & 2 & 1,90 & 31,0 & & \\
\hline Mundo Novo/ Robusta & 1 & 1 & 1 & 1 & 2 & 1,10 & 16,5 & & \\
\hline Catuaí/ Catuaí & 2 & 2 & 2 & 2 & 2 & 2,10 & 33,5 & & \\
\hline Mundo Novo/Mundo Novo & 2 & 1 & 1 & 2 & 1 & 1,50 & 21,5 & & \\
\hline Mundo Novo & 1 & 1 & 1 & 2 & 2 & 1,30 & 21,0 & & \\
\hline Catuaí & 2 & 2 & 1 & 2 & 2 & 1,90 & 30,0 & & \\
\hline
\end{tabular}

(') Catuaí = 'Catuaí Vermelho IAC 81'; Apoatã = 'Apoatã IAC 2258' (porta-enxerto); Mundo Novo = 'Mundo Novo IAC 515-20'; Bangelan $=$ C. congensis 'Bangelan col. $5^{\prime}$ (porta-enxerto); Robusta = 'Robusta IAC 2286'. (') Notas 1: $1 \%$ a 25\% de ramos com sintomas (aparentemente sadia); 2 : de $26 \%$ a $50 \%$ de ramos com sintomas (pouco infectada); 3: $51 \%$ a $75 \%$ de ramos com sintomas (moderadamente infectada); $4: 76 \%$ a $100 \%$ de ramos com sintomas (muito infectada). $\left(^{3}\right) \mathrm{R}=$ somatório do número de ordem; $\mathrm{K} 1=$ estatística $\mathrm{K}$ ajustado; $\mathrm{P}=$ probabilidade; NS = não significativo pelo teste de Friedman.

A severidade foi maior em 2004 do que em 2003, embora 2003 tenha sido mais seco, segundo dados meteorológicos do Centro de Pesquisa de Ecofisiologia e Biofísica do IAC. No período chuvoso de 2004, a severidade diminuiu, não havendo diferença entre os tratamentos.

A severidade do sintoma externo da presença da bactéria, observada em 2003 (Tabela 3), coincidiu com a verificada no período seco (antes do decote) de 2000 , e com os períodos seco e chuvoso de 2002, antes e após o decote respectivamente (QUEIROZ-VolTAN et al., 2004b). No período chuvoso de 2000 e no seco de 2004 ocorreu maior severidade de sintoma externo, porém, os tratamentos com maior e menor severidade no período chuvoso de 2000 diferiram daqueles obtidos no período seco de 2004 (Tabela 4).
As plantas em 2001estavam com sintomas típicos da doença (Figura 1A e B), persistindo até o ano seguinte quando foi realizado o decote (Figura 1C e D). O cafeeiro, seis meses após a poda, estava vigoroso, embora fosse um período de seca (abril/2003) (Figura 1E e F). Entretanto, passados outros seis meses, ou seja, um ano após o decote (dezembro/2003), as plantas já começaram a ter sintomas de infecção no ápice da planta, região que foi submetida ao desbaste (Figura 1G e H).

No período seco do ano seguinte (junho de 2004), vinte meses após a poda, pode-se observar o cafeeiro com os ramos do ápice em roseta (Figura 1 I), assim como no próximo período chuvoso desse mesmo ano (Figura $1 \mathrm{~J}$ ). 
Tabela 4. Níveis de severidade ocasionados pela bactéria Xylella fastidiosa em cultivares de cafeeiros de pé-franco e enxertados após a poda do tipo decote, em Garça (SP) em 2004, nos períodos de seca e chuvoso

\begin{tabular}{|c|c|c|c|c|c|c|c|c|c|}
\hline \multirow[t]{2}{*}{ Tratamentos $\left({ }^{1}\right)$} & \multicolumn{5}{|c|}{$\begin{array}{l}\text { Notas referentes a níveis de severiadade } \\
\text { nas parcelas }\left({ }^{2}\right)\end{array}$} & \multicolumn{4}{|c|}{ Parâmetros estatísticos $\left({ }^{3}\right)$} \\
\hline & A & $\mathrm{B}$ & $\mathrm{C}$ & $\mathrm{D}$ & $\mathrm{E}$ & Mediana & $\mathrm{R}$ & K1 & $\mathrm{P}$ \\
\hline & \multicolumn{8}{|c|}{ Período de seca } & \\
\hline Catuaí/ Apoatã & 2 & 3 & 3 & 2 & 3 & 2,65 & 40,5 & 24,60 & 0,003 ** \\
\hline Catuaí/ Bangelan & 2 & 2 & 3 & 2 & 1 & 2,05 & 31,0 & & \\
\hline Catuaí/Robusta & 2 & 2 & 2 & 2 & 2 & 1,95 & 32,0 & & \\
\hline Mundo Novo/ Apoatã & 3 & 3 & 3 & 2 & 2 & 2,85 & 41,0 & & \\
\hline Mundo Novo/Bangelan & 2 & 1 & 3 & 1 & 3 & 2,15 & 29,0 & & \\
\hline Mundo Novo/ Robusta & 2 & 3 & 1 & 2 & 2 & 2,25 & 32,0 & & \\
\hline Catuaí/ Catuaí & 1 & 1 & 1 & 2 & 1 & 1,05 & 17,0 & & \\
\hline Mundo Novo/Mundo Novo & 1 & 2 & 2 & 2 & 1 & 1,55 & 23,5 & & \\
\hline Mundo Novo & 1 & 1 & 1 & 2 & 1 & 1,05 & 17,0 & & \\
\hline \multirow[t]{2}{*}{ Catuaí } & 1 & 1 & 1 & 1 & 1 & 0,95 & 12,0 & & \\
\hline & \multicolumn{8}{|c|}{ Período chuvoso } & \\
\hline Catuaí/Apoatã & 2 & 4 & 1 & 3 & 1 & 2,25 & 32,5 & 6,94 & $0,644 \mathrm{NS}$ \\
\hline Catuaí/ Bangelan & 1 & 2 & 4 & 2 & 3 & 1,95 & 32,5 & & \\
\hline Catuaí/ Robusta & 2 & 2 & 1 & 2 & 2 & 1,85 & 28,0 & & \\
\hline Mundo Novo/ Apoatã & 2 & 1 & 4 & 1 & 2 & 2,05 & 27,5 & & \\
\hline Mundo Novo/Bangelan & 2 & 2 & 3 & 3 & 1 & 2,15 & 33,0 & & \\
\hline Mundo Novo/IAC 2286 & 1 & 2 & 1 & 2 & 1 & 1,35 & 18,5 & & \\
\hline Catuaí/ Catuaí & 1 & 2 & 2 & 3 & 2 & 2,05 & 30,5 & & \\
\hline Mundo Novo/Mundo Novo & 1 & 3 & 2 & 2 & 1 & 1,55 & 26,0 & & \\
\hline Mundo Novo & 2 & 2 & 2 & 1 & 2 & 1,95 & 28,0 & & \\
\hline Catuaí & 1 & 2 & 1 & 2 & 1 & 1,35 & 18,5 & & \\
\hline
\end{tabular}

$\left({ }^{1}\right)$ Catuaí = 'Catuaí Vermelho IAC81'; Apoatã = 'Apoatã IAC 2258' (porta-enxerto); Mundo Novo = 'Mundo Novo IAC 515-20'; Bangelan = C. congensis 'Bangelan col. 5' (porta-enxerto); Robusta = 'Robusta IAC 2286' (porta-enxerto). ( ${ }^{2}$ ) Notas 1: 1\% a 25\% de ramos com sintomas (aparentemente sadia); 2: de $26 \%$ a $50 \%$ de ramos com sintomas (pouco infectada); $3: 51 \%$ a $75 \%$ de ramos com sintomas (moderadamente infectada); $4: 76 \%$ a $100 \%$ de ramos com sintomas (muito infectada). $\left({ }^{3}\right) \mathrm{R}=$ somatório do número de ordem; $\mathrm{K} 1=$ estatística $\mathrm{K}$ ajustado; $\mathrm{P}=$ probabilidade; NS= não significativo pelo teste de Friedman; ** significativo a 1\% pelo teste de Friedman.

Alguns trabalhos demonstraram que plantas de C. arabica enxertadas sobre C. canephora tinham mais capacidade em absorver e translocar água para a parte aérea durante período de estresse hídrico no solo, em relação às plantas de C. arabica não enxertadas (FAHL et al., 1998, 2001). Desse modo, seria esperado que o efeito da X. fastidiosa fosse menor em plantas de C. arabica enxertadas sobre C. canephora, pois diminuiria os riscos de estresse hídrico provocados pela bactéria. Entretanto, no período chuvoso de 2000, na 'Catuaí Vermelho IAC 81' enxertada sobre IAC Bangelan e na 'Mundo Novo IAC 515-20' enxertada sobre C. canephora 'IAC 2286' ocorreram menores sintomas externos de infecção, enquanto no período seco de 2004, nos tratamentos enxertados, observou-se maior severidade. Esses dados reforçam resultados anteriores (QueIrozVoltAn et al., 2004b) de que a severidade não está diretamente relacionada com a disponibilidade de água em cafeeiro.

Quando se comparam todos os períodos em que foi estimada a severidade do sintoma externo após o decote, de 2002 a 2004 (Tabela 5), verifica-se que houve diferenças apenas para a 'Catuaí Vermelho IAC 81' enxertada sobre ela mesma e pé-franco, com severidade menor em relação aos outros tratamentos no período de seca de 2004. É importante reforçar que esse período foi aquele cujos sintomas de severidade da doença foram maiores. 

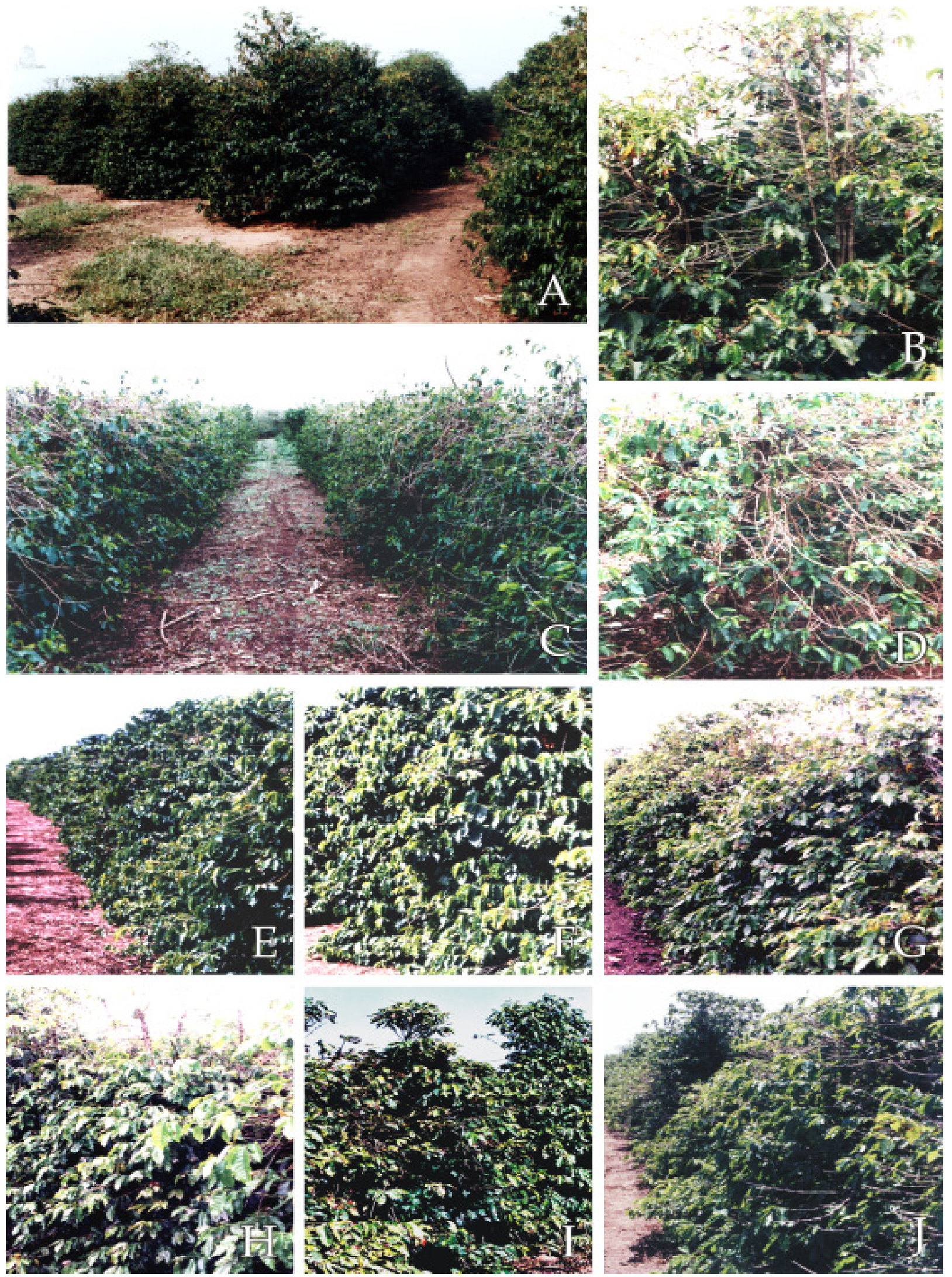

Figura 1. Efeito da poda do tipo decote no controle da X. fastidiosa em cafeeiro. A e B- Antes da poda (set./2001); C e D- Um mês após a poda (nov./2002); E e F- Seis meses após a poda (abril/2003); G e H- Quatorze meses após a poda (dez./2003); I -Vinte meses após a poda (junho/2004); J- Vinte e seis meses após a poda (dez./2004). 
Tabela 5. Comparações dos níveis de severidade ocasionados pela bactéria Xylella fastidiosa em cultivares de cafeeiros de pé-franco e enxertados, após a poda do tipo decote, Garça (SP), 2002 a 2004, no período de seca (P1) e chuvoso (P2)

\begin{tabular}{|c|c|c|c|c|c|c|c|c|c|c|c|c|}
\hline \multirow{4}{*}{ Tratamentos $\left({ }^{1}\right)$} & \multicolumn{12}{|c|}{ Parâmetros estatísticos $\left({ }^{2}\right)$} \\
\hline & \multirow{2}{*}{\multicolumn{2}{|c|}{$\begin{array}{c}2002 \\
\text { P2 }\end{array}$}} & \multicolumn{4}{|c|}{2003} & \multicolumn{4}{|c|}{2004} & \multirow[b]{3}{*}{ K1 } & \multirow[b]{3}{*}{$\mathrm{P}$} \\
\hline & & & \multicolumn{2}{|c|}{ P1 } & \multicolumn{2}{|c|}{ P2 } & \multicolumn{2}{|c|}{ P1 } & \multicolumn{2}{|c|}{$\mathrm{P} 2$} & & \\
\hline & M & $\mathrm{R}$ & M & $\mathrm{R}$ & $\mathrm{M}$ & $\mathrm{R}$ & M & $\mathrm{R}$ & M & $\mathrm{R}$ & & \\
\hline Catuaí/ IAC 2258 & 2,0 & 14,0 & 1,8 & 9,5 & 2,6 & 14,5 & 2,8 & 20,0 & 2,8 & 17,0 & 5,76 & $0,22 \mathrm{NS}$ \\
\hline Catuaí/ Bangelan & 2,0 & 14,5 & 1,6 & 12,0 & 1,8 & 14,0 & 2,2 & 16,0 & 2,4 & 18,5 & 2,69 & $0,61 \mathrm{NS}$ \\
\hline Catuaí/IAC 2286 & 2,0 & 12,5 & 2,0 & 14,5 & 2,0 & 15,0 & 2,0 & 17,5 & 2,0 & 15,5 & 1,58 & $0,81 \mathrm{NS}$ \\
\hline M. Novo/ IAC 2258 & 3,0 & 20,5 & 2,0 & 10,0 & 2,4 & 15,0 & 2,8 & 18,0 & 1,8 & 11,5 & 7,56 & $0,11 \mathrm{NS}$ \\
\hline M. Novo/Bangelan & 2,0 & 14,5 & 1,8 & 11,5 & 2,2 & 16,0 & 2,0 & 15,5 & 2,0 & 17,5 & 2,29 & $0,68 \mathrm{NS}$ \\
\hline M. Novo/IAC 2286 & 1,2 & 15,5 & 1,0 & 10,5 & 1,0 & 13,0 & 1,8 & 21,0 & 1,0 & 15,0 & 8,64 & $0,07 \mathrm{NS}$ \\
\hline Catuaí/ Catuaí & 2,0 & 15,0 & 2,0 & 17,5 & 2,0 & 17,5 & 1,0 & 7,5 & 2,0 & 17,5 & 9,23 & $0,05+$ \\
\hline M. Novo/ M. Novo & 2,0 & 21,0 & 1,0 & 10,5 & 1,0 & 13,0 & 1,0 & 14,5 & 1,0 & 16,0 & 8,07 & $0,09 \mathrm{NS}$ \\
\hline M. Novo & 1,8 & 18,0 & 1,8 & 15,5 & 1,4 & 13,0 & 1,0 & 10,5 & 2,0 & 18,0 & 4,86 & $0,30 \mathrm{NS}$ \\
\hline Catuaí & 2,0 & 18,5 & 2,0 & 16,0 & 2,0 & 18,5 & 1,2 & 8,5 & 1,8 & 13,5 & 10,18 & $0,04+$ \\
\hline
\end{tabular}

$\left({ }^{1}\right)$ Catuaí = 'Catuaí Vermelho IAC 81'; Apoatã = 'Apoatã IAC 2258' (porta-enxerto); Mundo Novo = 'Mundo Novo IAC 515-20'; Bangelan = C. congensis 'Bangelan col. 5' (porta-enxerto); Robusta = 'Robusta IAC 2286' (porta-enxerto). $\left({ }^{2}\right.$ ) Notas 1: 1\% a 25\% de ramos com sintomas (aparentemente sadia); 2: de $26 \%$ a $50 \%$ de ramos com sintomas (pouco infectada); $3: 51 \%$ a $75 \%$ de ramos com sintomas (moderadamente infectada); $4: 76 \%$ a $100 \%$ de ramos com sintomas (muito infectada); $\mathrm{M}=$ Nota Mediana; $\mathrm{R}=$ somatório do número de ordem; $\mathrm{K} 1=\mathrm{estatística}$ $\mathrm{K}$ ajustado; $\mathrm{P}=$ probabilidade; $\mathrm{NS}=$ não significativo; + = significativo a $5 \%$ pelo teste de Friedman.

Segundo CARELLi et al. (1989), tanto o período de chuvas como o de estresse hídrico coincidem com os períodos de maior atividade do cafeeiro, ou seja, floração e enchimento de grãos (formação do endosperma) respectivamente. Portanto, a planta necessita de um transporte rápido de água e nutrientes para as estruturas reprodutivas e órgãos fotossintéticos. Ademais, na fase de enchimento de grãos, estes acumulam cerca de $80 \%$ de água (CANNEL, 1975). A maior obstrução dos vasos do xilema, ocasionada pela $X$. fastidiosa no período de estresse hídrico, pode ser a causa do menor desenvolvimento dos frutos que estão em expansão.

Como a poda do tipo decote consiste na eliminação apenas do ápice da planta e a X. fastidiosa se distribui por todos os ramos do cafeeiro, esse tipo de poda não foi efetivo no controle dessa doença.

Sabe-se que essa bactéria coloniza algumas células do xilema, enquanto outros vasos adjacentes estão desprovidos da bactéria, daí a alta variância observada na obstrução dos vasos. O mecanismo da movimentação da bactéria de célula a célula ainda não foi esclarecido. Sabe-se, porém, que o processo é lento e que a translocação da bactéria na planta depende não só da virulência da estirpe, mas do grau de resistência e da idade da planta hospedeira, já que a bactéria parece se multiplicar melhor em plantas mais maduras do que em novas, o que pode estar associado à transpiração e ao transporte via xilema (HiLl E Purcell, 1995). O movimento sistêmico da X. fastidiosa dentro do xilema da planta é essencial para a habilidade da bactéria de causar doenças e, provavelmente, para a sua sobrevivência no ambiente natural.

A diminuição na proporção da obstrução dos elementos de vaso do xilema, observada em 2003, foi pequena e a severidade do sintoma externo aumentou em 2004, deduzindo que a prática desse tipo de poda foi insuficiente.

Embora não se conheça o mecanismo de multiplicação e translocação da X. fastidiosa no seu hospedeiro, já era esperado que a poda seria uma medida de controle temporário, porque apesar de brotarem ramos novos, sem a presença da bactéria, são novamente colonizados pelo patógeno pelas cigarrinhas portadoras da bactéria, após um tempo ainda desconhecido. A similaridade na proporção da obstrução no período chuvoso, antes e após a poda, leva a pensar que houve o retorno aos índices iniciais de infecção dos elementos de vaso do xilema.

\section{CONCLUSÃO}

A prática da poda do tipo decote não resultou, neste experimento, em controle eficiente da $X$. fastidiosa em cafeeiros arábica cultivares 'Catuaí Vermelho IAC 81' e 'Mundo Novo IAC 515-20' de pé-franco ou enxertados, previamente infectados por essa moléstia. 


\section{AGRADECIMENTOS}

Ao Pesquisador Científico do IAC, Armando Conagin, pela orientação nas análises estatísticas. Ao proprietário da Fazenda da Mata (Garça, SP), Sr. Nízio Bonini, e aos Engenheiros Agrônomos da GARCAFÉ, Gustavo Guerreiro e José Antônio de Mendonça Otoboni pelo manejo da cultura.

\section{REFERÊNCIAS}

CARELLI, M.L.C.; FAHL, J.I.; MAGALHÃES, A.C. Assimilação de nitrato durante o desenvolvimento reprodutivo de plantas de café. Revista Brasileira de Ciência do Solo, Campinas, v.13, p.59-64, 1989.

CANNEL, M.G.R. Crop physiological aspects of coffee bean yield: a review. Journal of Coffee Research, Karnataka, v.5, p.7-20, 1975.

ESAU, K. Anatomic effects of the viruses of pierce's disease and phony peach. Hilgardia, Berkeley, v.18, n.12, p.423-482, 1948.

FAHL, J.I.; CARELLI, M.L.C.; GALLO, P.B.; COSTA, W.M.; NOVO, M.C.S.S. Enxertia de Coffea arabica sobre progênies de $C$. canephora e de C. congensis no crescimento, nutrição mineral e produção. Bragantia, Campinas, v.57, n.2, p.297-312, 1998.

FAHL, J.I.; CARELLI, M.L.C.; MENEZES, H.C.; GALLO, P.B.; TRIVELIN, P.C.O. Gas exchange, growth, yield and beverage quality of Coffea arabica cultivars grafted on to C. canephora and C. congensis. Experimental Agriculture, London, v.37, p.241$252,2001$.

FAZUOLI, L.C.; COSTA, W.M.; BORTOLETTO, N. Efeitos do porta-enxerto IAC 2258 de Coffea canephora, resistente a Meloidogyne incognita, no desenvolvimento e produção iniciais de dois cultivares de Coffea arabica. In: CONGRESSO BRASILEIRO DE PESQUISAS CAFEEIRAS, 10, Poços de Caldas, 1983. Anais... Rio de Janeiro, MIC/IBC, 1983. p.113-115.

FEICHTENBERGER, E.; MÜLLER, G.W.; GUIRADO, N. Doença dos citros. In: KIMATI, H.; AMORIM, L.; BERGAMIN FILHO, A. CAMARGO, L.E.A.; REZENDE, J.A.M. (Ed.) Manual de Fitopatologia: doenças das plantas cultivadas. São Paulo, v.2, p.262-296, 1997.

FRENCH, W.J.; STASSI, D.L. Response of phony- infected peach trees to gibberellic acid. HortScience, Alexandria, v.13, n.2, p.158-159, 1978.

GABRIELLI, A.C. Contribuição ao estudo anatômico da raiz de Pyrostegia venusta (Ker) Miers-Bignoniaceae. Revista Brasileira de Botânica, São Paulo, v.15, n.2, p.95-104, 1992.

GOMES, F.P. Curso de Estatística Experimental. 13.ed. Piracicaba: Livraria Nobel, 1990. 468p.
HABERMANN, G.; MACHADO, E.C.; RODRIGUES, J.D.; MEDINA, C.L. $\mathrm{CO}_{2}$ assimilation, photosynthetic light response curves, and water relations of 'Pêra' sweet orange plants infected with Xylella fastidiosa. Brazilian Journal Plant Physiology, Campinas, v.15, n.2, p.79-87, 2003.

HILL, B.L.; PURCELL, A.H. Multiplication and movement of Xylella fastidiosa within grapevine and four other plants. Phytopathology, St. Paul, v.85, n.11, p.1368-1372, 1995.

HOPKINS, D.L. Seasonal concentration of the Pierce's disease bacterium in grapevine stems, petioles and leaf veins. Phytopathology, St. Paul, v.71, p.415-418, 1981.

HOPKINS, D.L. Xylella fastidiosa: xylem-limited bacterial pathogen of plants. Annual Review Phytopathology, Palo Alto, v.27, p.271-290, 1989.

HOPKINS, D.L.; ADLERZ, W.C. Natural hosts of Xylella fastidiosa in Florida. Plant Disease, St. Paul, v.72, p.429-431, 1988.

JOHANSEN, D.A. Plant microtechnique. New York, McGrawHill, 1940. 523p.

LEE, R.F.; RAJU, B.C.; NYLAND, G.; GOHEEN, A.C. Phytotoxin (s) produced in culture by the Pierce's disease bacterium. Phytopathology, St. Paul, v.72, p.886-888, 1982.

LOPES, J.R.S. Mecanismos de transmissão de Xylella fastidiosa por cigarrinhas. Laranja, Cordeirópolis, v.17, n.1, p.79-92, 1996.

MACHADO, E.C.; QUAGGIO, J.A.; LAGÔA, A.M.M.A.; TICELLI, M..; FURLANI, P.R. Trocas gasosas e relações hídricas em laranjeiras com clorose variegada dos citros. Revista Brasileira de Fisiologia Vegetal, São Carlos, v.6, p.53-57, 1994.

McELRONE, A.J.; SHERALD, J.L.; FORSETH, I.N. Interactive effects of water stress and xylem-limited bacterial infection on the water relations of a host vine. Journal of Experimental Botany, Oxford, v.54, n.381, p.419-430, 2003.

MIRCETICH, S.M.; LOWE, S.K.; MOLLER, W.J.; NYLAND, G. Etiology of almond leaf scorch disease and transmission of the causal agent. Phytopathology, St. Paul, v.66, p.17-24, 1976.

MOLLENHAUER, H.A.; HOPKINS, D.L. Xylem morphology of Pierce's disease-infected grapevines with different levels of tolerance. Physiological Plant Pathology, New York, v.9, p.95-100, 1976.

PAIVA, P.E.B.; SILVA, J.L.; GRAVENA, S.; YAMAMOTO, P.T. Cigarrinhas de xilema em pomares de laranja do Estado de São Paulo. Laranja, Cordeirópolis, v.17, n.1, p.41-54, 1996.

PARADELA FILHO, O.; SUGIMORI, M.H.; RIBEIRO, I.J.A.; GARCIA JUNIOR, A.; BERETTA, M.J.G.; HARAKAWA, R.; MACHADO, M.A.; LARANJEIRA, F.F.; RODRIGUES NETO, J.; BERIAM, L.O.S. Primeira constatação em cafeeiro no Brasil da Xylella fastidiosa causadora da clorose variegada dos citros. Laranja, Cordeirópolis, v.16, n.2, p.135-136, 1995.

PARADELA FILHO, O.; SUGIMORI, M.H.; RIBEIRO, I.J.A.; 
GARCIA JUNIOR, A.; BERETTA, M.J.G.; HARAKAWA, R.; MACHADO, M.A.; LARANJEIRA, F.F.; RODRIGUES NETO, J.; BERIAM, L.O.S. Constatação de Xylella fastidiosa em cafeeiro no Brasil. Summa Phytopathologica, Jaboticabal, v.23, p.46-49, 1997.

PARADELA FILHO, O.; THOMAZIELLO, R.A.; BERETTA, M.J.G.; FAZUOLI, L.C.; OLIVEIRA, E.G. de; FAHL, J.I.; PEZZOPANE, J.R.M. Atrofia dos ramos de cafeeiro, causada por Xylella fastidiosa. Campinas: Instituto Agronômico, 1999. 10p. (Boletim Técnico, 182).

PIERCE, N.B. The Califórnia Vine Disease. Colorado: U.S. Bureau of Agriculture, Division of vegetable Pathology, 1892. 205p. (Bulletin, n.2)

PRATO, J.R.A. Quem diria, a Xylella fastidiosa sempre esteve no café. A Granja, São Paulo? fevereiro/2000, 614, p.40-43, 2000.

QUEIROZ-VOLTAN, R.B.; PARADELA FILHO, O.; CARELLI, M.L.C.; FAHL, J.I. Aspectos estruturais de cafeeiro infectado com Xylella fastidiosa. Bragantia, Campinas, v.57, n.1, p.23-33, 1998.

QUEIROZ-VOLTAN, R.B.; CABRAL, L.P.; PARADELA FILHO, O. Comparações sazonais do efeito da Xylella fastidiosa em cultivares de cafeeiro. Bragantia, Campinas, v.63, n.3, p.381393, 2004a.

QUEIROZ-VOLTAN, R.B.; CABRAL, L.P.; PARADELA FILHO, O. Severidade do sintoma da bactéria Xylella fastidiosa em cultivares de cafeeiro. Bragantia, Campinas, v.63, n.3, p.395404, 2004b.
QUEIROZ-VOLTAN, R.B.; CABRAL, L.P.; PARADELA FILHO, O.; CARELLI, M.L.C.; FAHL, J.I.; FAZUOLI, L.C. Efeito da Xylella fastidiosa em cafeeiro em diferentes regiões edafoclimáticas. Bragantia, Campinas, v.64, n.1, p.89-100, 2005.

RAIJ, B. van; CANTARELLA, H.; QUAGGIO, J.A. Estimulantes. In: RAIJ, B.van; CANTARELLA, H.; QUAGGIO, J.A.; FURLANI, A.M.C. (Ed.). Recomendações de adubação e calagem para o Estado de São Paulo. 2. ed. Campinas: Instituto Agronômico \& Fundação IAC, 1997. 285p. (Boletim técnico, 100)

SOKAL, R.R.; ROHLF, F.J. Biometry. 2ed. New York: W.F. Freeman, 1981. 859p.

SPRENT, P. Applied Nonparametric Statistical Methods. 2.ed. London: Chapman \& Hall, 1996. 342p.

THOMAZIELLO, R. A.; FAZUOLI, L.C.; PEZZOPANE, J.R.M.; FAHL, J.I.; CARELLI, M.L.C. Café arábica: cultura e técnicas de produção. Campinas: Instituto Agronômico, 2000. 82p. (Boletim Técnico, 187)

WEBER, E.; Purcell, A.H.; NORBERG, E. Severe pruning for management of Pierce's disease. American Journal of Enology and Viticulture, Davis, v.51, p.293, 2000.

WEBER, E.; Purcell, A. H.; NORBERG, E. Limited effectiveness of severe pruning for managing Pierce's disease. In: ANNUAL MEETING OF THE AMERICAN SOCIETY FOR ENOLOGY AND VITICULTURE, 53., 2002, Portland. Proceedings... Davis: American Society for Enology and Viticulture, 2002. p.26-28. 